\title{
Broadband Loop Antenna on Soft Contact Lens for Wireless Ocular Physiological Monitoring
}

\author{
Ssu-Han Ting, ${ }^{1}$ Bo-Ming Jeng, ${ }^{1}$ Wen-Shan Chen, ${ }^{2}$ \\ Jin-Chern Chiou, ${ }^{3}$ and Ching-Hsing Luo ${ }^{1,4}$ \\ ${ }^{1}$ Department of Electrical Engineering, National Cheng Kung University, Tainan City 701, Taiwan \\ ${ }^{2}$ Department of Electronic Engineering, Southern Taiwan University of Science and Technology, Tainan City 71005, Taiwan \\ ${ }^{3}$ Department of Electronic and Computer Engineering, National Chiao Tung University, Hsinchu 30010, Taiwan \\ ${ }^{4}$ Institute of Medical Science and Technology, National Sun Yat-sen University, Kaohsiung, 804, Taiwan \\ Correspondence should be addressed to Ching-Hsing Luo; robinluo@mail.ncku.edu.tw
}

Received 28 September 2013; Revised 9 March 2014; Accepted 9 March 2014; Published 13 April 2014

Academic Editor: Zhongxiang Shen

Copyright (C) 2014 Ssu-Han Ting et al. This is an open access article distributed under the Creative Commons Attribution License, which permits unrestricted use, distribution, and reproduction in any medium, provided the original work is properly cited.

\begin{abstract}
This paper presents a novel loop antenna with broadband for wireless ocular physiological monitoring (WOPM). The antenna is fabricated on a thin-film poly-para-xylylene C (parylene C) substrate with a small thickness of $11 \mu \mathrm{m}$ and dimension of $\pi \times 6.5 \times$ $6.5 \mathrm{~mm}^{2}$. With the advantage of small size, the proposed antenna is suitable to apply to the soft contact lens and transmit the signal in microelectromechanical Systems (MEMS). Because the pig's eye and human's eye have similar parameters of conductivity and permittivity, the experimental results are obtained by applying the proposed antenna on the pig's eye and cover from 1.54 to $6 \mathrm{GHz}$ for ISM band $(2.4$ and $5.8 \mathrm{GHz})$ applications. The measured antenna radiation patterns, antenna gains, and radiation efficiency will be demonstrated in this paper, which are suitable for application of wireless ocular physiological monitoring.
\end{abstract}

\section{Introduction}

Recently, monitoring various physiological parameters with biological telemetry system has become an important research topic in wireless monitoring control. To accomplish the wireless monitoring control, the antennas implanted in human body are used to establish communication links between medical sensing devices and external instruments for short-distance biotelemetry. Eye ball monitoring system that is an application of biological telemetry system has also been studied recently, such as monitoring intraocular pressure monitoring systems $[1,2]$, wireless powered microLED display systems [3], and glucose-monitoring systems [4]. This biotelemetry system can transfer the physiological data into signal and transmit the signal to the external receiving instrument through the antenna on the contact lens. These instruments can share valuable data through the telephone system or the Internet. Through the wireless instruments, the detected physiological data can be sent regularly to the medical institution. An antenna is a key component in the biotelemetry medical systems to transfer available data. However, the antennas used in human body are difficult to accomplish for interference and size limits. This paper presents a novel loop antenna design for WOPM applications.

\section{Antenna Design}

2.1. Antenna Geometry. Using the Ansoft simulation software high-frequency structure simulator (HFSSTM), a novel broadband antenna was designed for the biotelemetry applications (ISM band 2.4 and $5.8 \mathrm{GHz}$ ). The geometry of the proposed antenna shown in Figure 1(a) is fabricated on the parylene $C$ substrate with thickness of $11 \mu \mathrm{m}$ and permittivity of 4 . Figure 1(b) shows the photograph of proposed antenna with minicable. The proposed antenna is connected on a soft contact lens with conductive epoxy glue. The overall dimension of loop antenna is $\pi \times 6.5 \times 6.5 \mathrm{~mm}^{2}$ with width of the $1 \mathrm{~mm}$ (W1). The parameters of the antenna are listed in Table 1. 


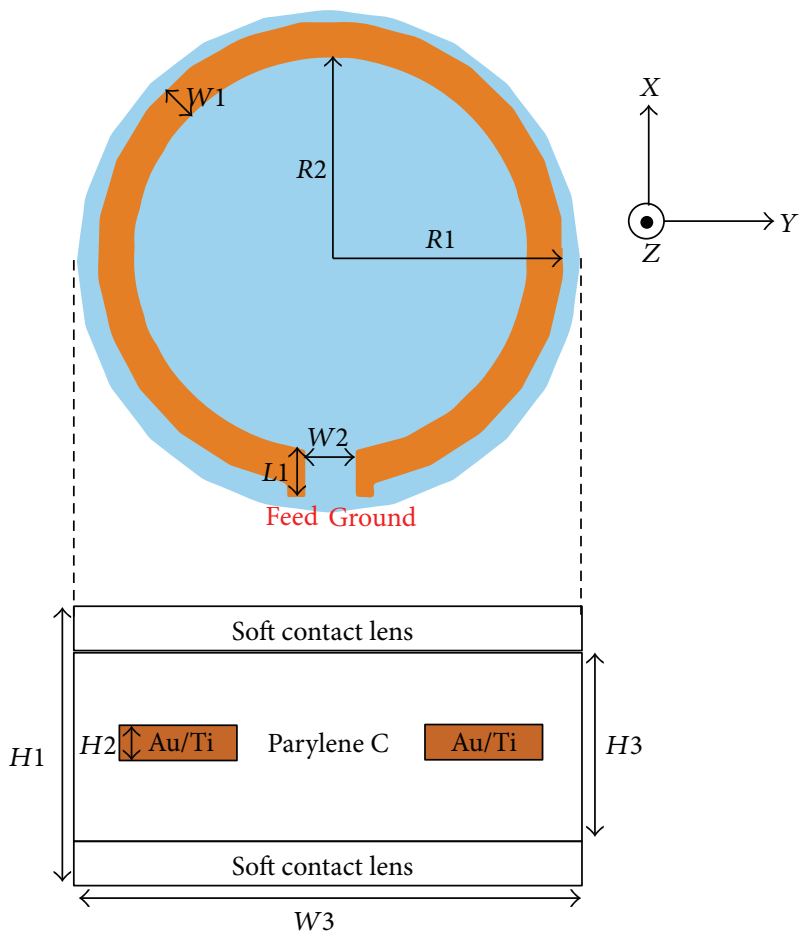

(a)

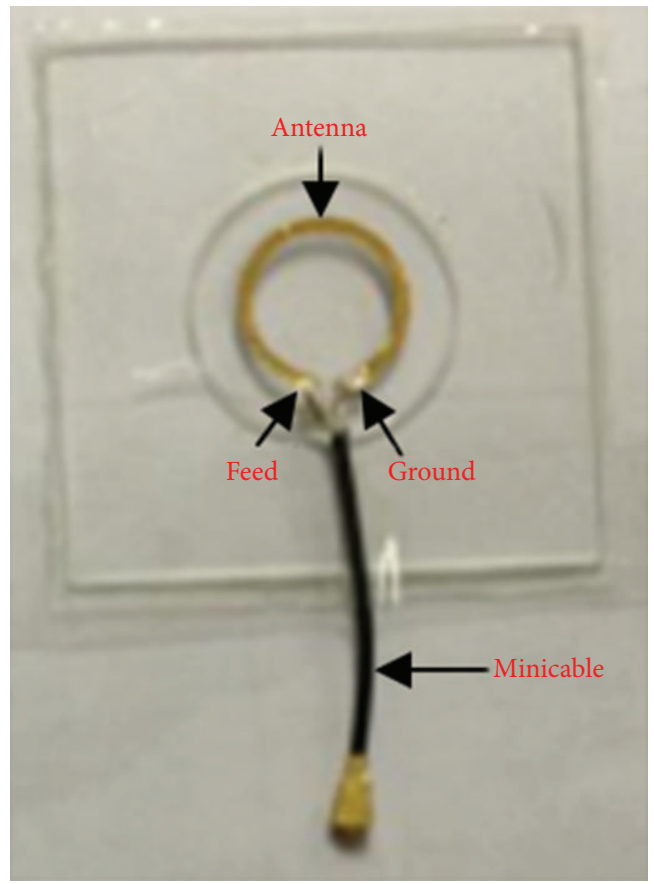

(b)

FIGURE 1: Geometry of the proposed antenna. (a) Substrate model. (b) Photograph of a fabricated antenna with minicable.

TABLE 1: Parameters of the proposed antenna.

\begin{tabular}{lccc}
\hline Parameter & Unit $(\mathrm{mm})$ & Parameter & Unit (um) \\
\hline$W 1$ & 1 & $H 1$ & 100 \\
$W 2$ & 1.4 & $H 2$ & 0.38 \\
$W 3$ & 7 & $H 3$ & 11 \\
$R 1$ & 6.5 & & \\
$R 2$ & 5.5 & & \\
$L 1$ & 1.3 & & \\
\hline
\end{tabular}

2.2. Comparison of Permittivity and Conductivity between Human's and Pig's Eye. In experimental operation, pig's eye must be used to replace human's eye. Therefore, the parameters of their tissue must be verified and studied. Figure 2 presents the measurement environment of the minced pig's eye tissue on an Agilent 85070E dielectric probe kit and an $8753 \mathrm{E}$ network analyzer. Figure 3 shows the comparison results of permittivity and conductivity against frequency between the test tissue (pig's eye) and the reference tissue (human's eye) [5]. The results indicate that the characteristics of pig's eye are similar to human's eye and can be used to replace human's eye.

\section{Results and Discussion}

The simulated results of the proposed antenna are obtained by high frequency structure simulator (HFSS) [6] and
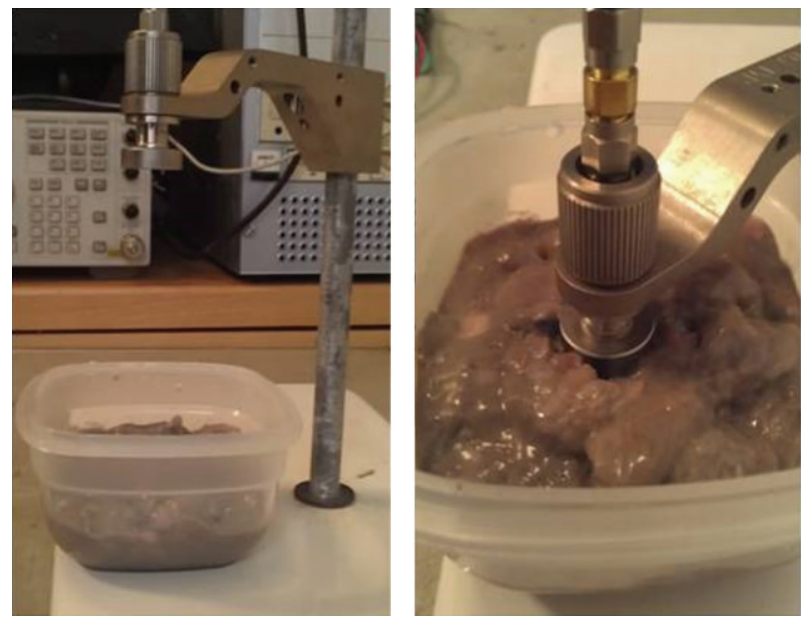

FIGURE 2: Minced pig's eye tissue measurement environment.

the measured results are achieved from Agilent E5071C network analyzer. In Figure 4, the measured and simulated antenna reflection coefficient $\left(S_{11}\right)$ of the proposed antenna demonstrates good agreement. Two resonant modes create wide operation bandwidth that can also be observed. The measured $S_{11}$ based on $-10 \mathrm{~dB}$ standard achieves an impedance bandwidth of $4.46 \mathrm{GHz}$ (from 1.54 to $6 \mathrm{GHz}$ ) for ISM application band. Figure 5 shows the simulated input impedance (imaginary and real parts) for the proposed antenna. From 1.75 to $6 \mathrm{GHz}$, the input impedance presents 


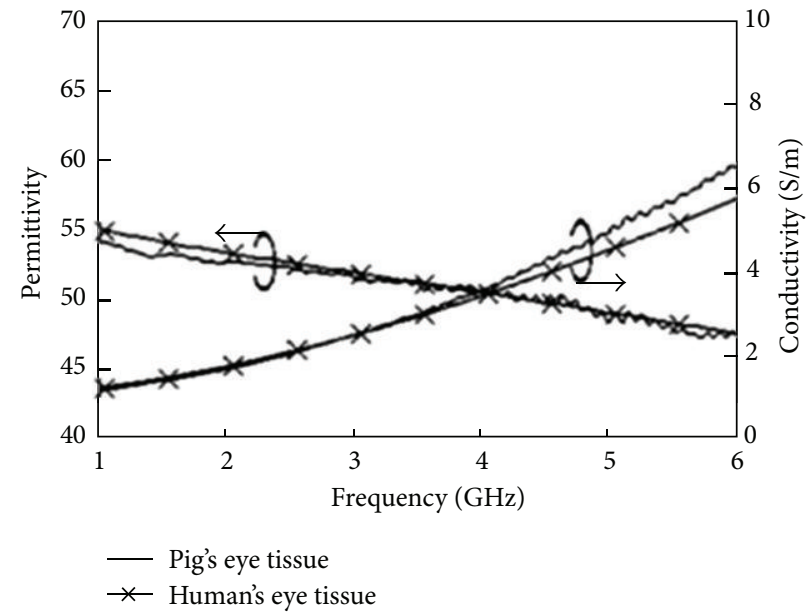

FIGURE 3: Comparing the permittivity and conductivity against frequency of the test tissue (pig's eye) and the reference tissue (human's eye).

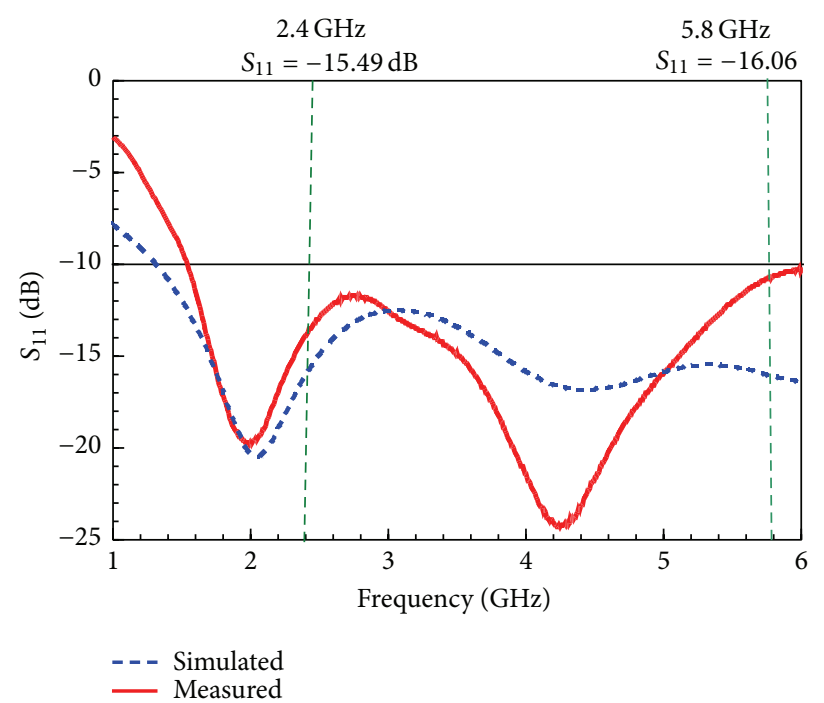

FIGURE 4: Simulated and measured return loss of the proposed antenna.

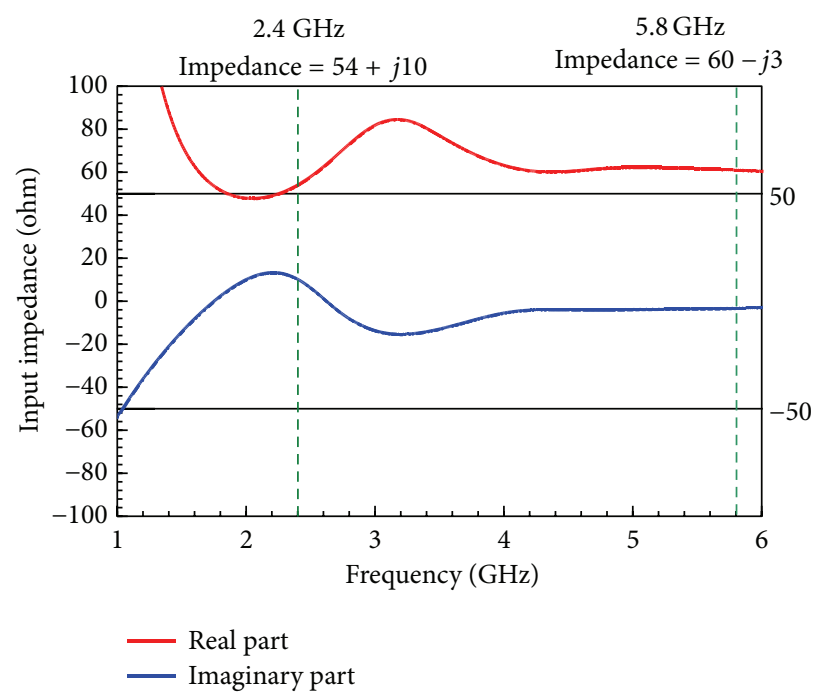

FIGURE 5: Simulated impedance of the proposed antenna. 


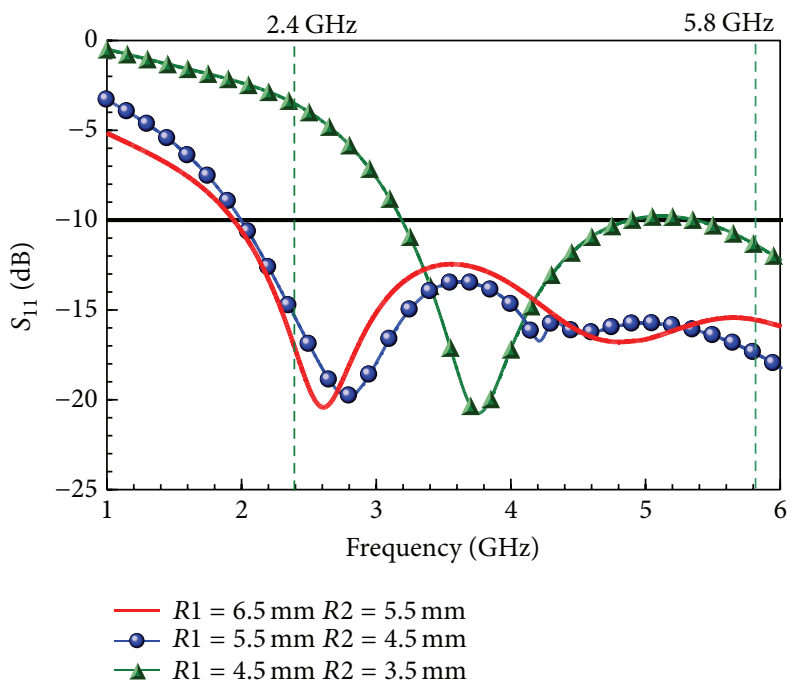

Figure 6: Simulated $S_{11}$ for different loop sizes of the proposed antenna.
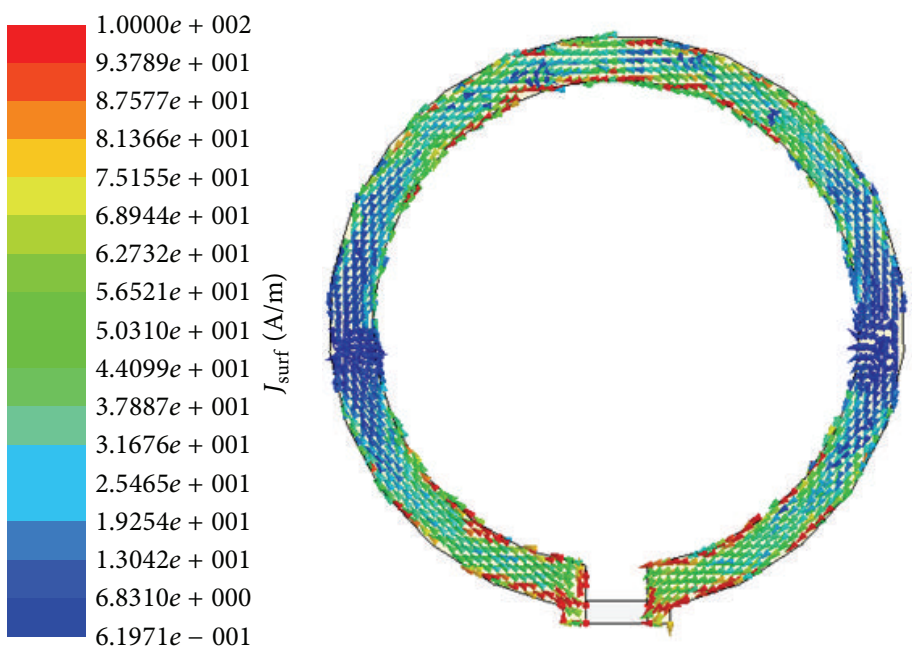

(a)

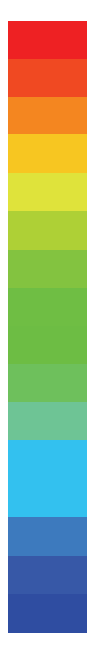
$5.0000 e+001$ $4.6879 e+001$
$4.3758 e+001$
$4.0638 e+001$
$3.7517 e+001$
$3.4396 e+001$
$3.1275 e+001$
$2.8155 e+001$
$2.5034 e+001$
$2.1913 e+001$
$1.8792 e+001$
$1.5672 e+001$
$1.2551 e+001$
$9.4300 e+000$
$6.3092 e+000$
$3.1884 e+000$
$6.7656 e-002$

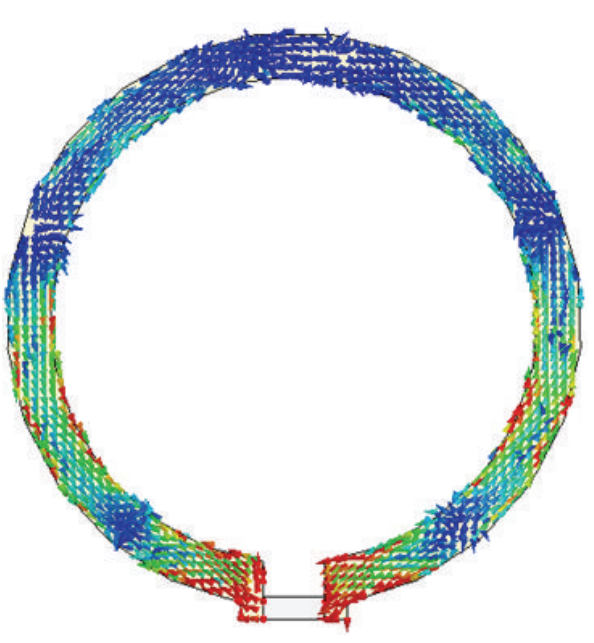

(b)

FiguRE 7: Simulated current distributions of the proposed antenna: (a) $2.4 \mathrm{GHz}$ (b) $5.8 \mathrm{GHz}$. 


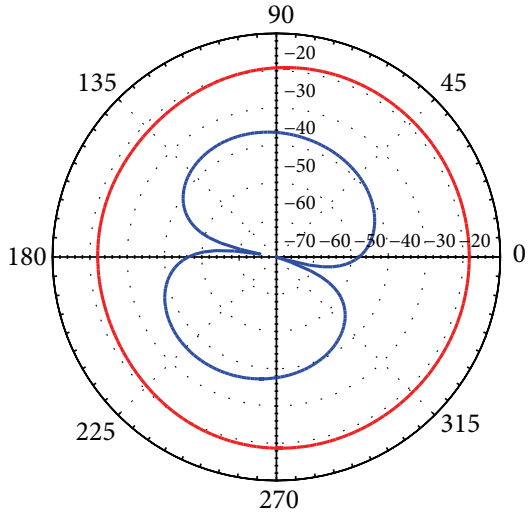

$Y-Z$ plane

- Co-pol

- Cro-pol

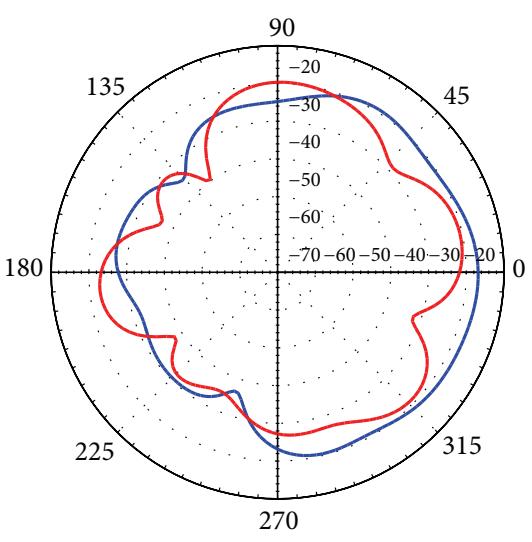

$Y-Z$ plane

- Co-pol

Cro-pol

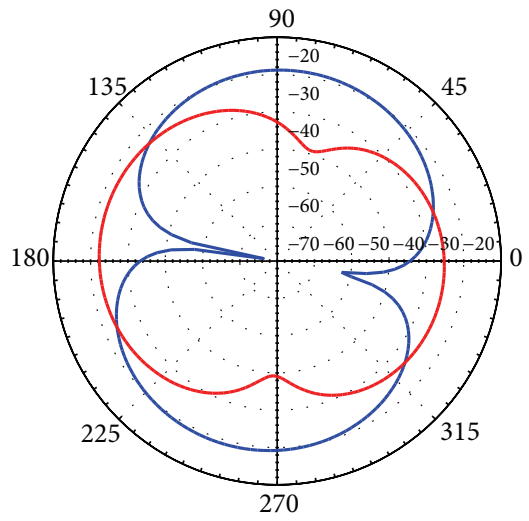

$X-Y$ plane

- Co-pol

- Cro-pol

(a)

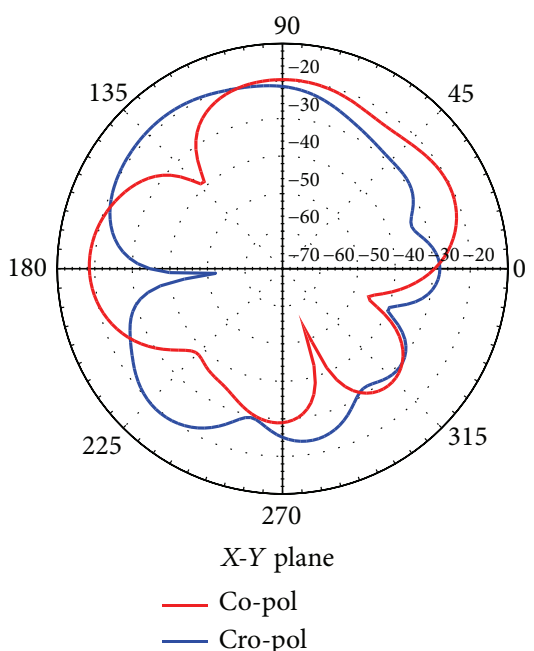

(b)
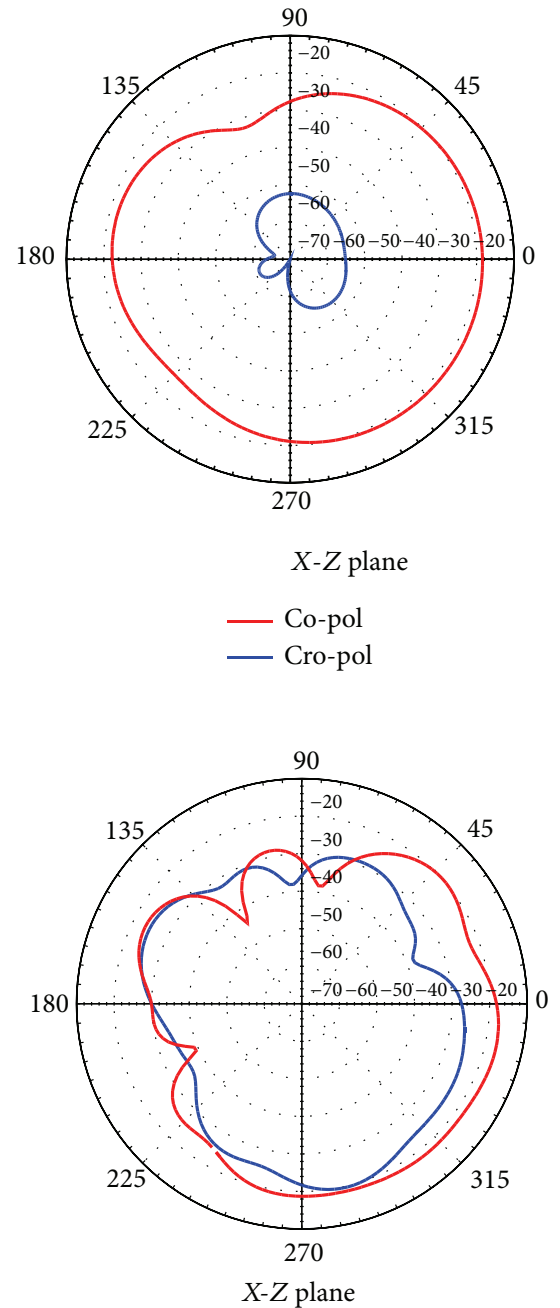

- Co-pol

FIGURE 8: Measured 2D radiation pattern of the proposed antenna: (a) $2.4 \mathrm{GHz}$; (b) $5.8 \mathrm{GHz}$.

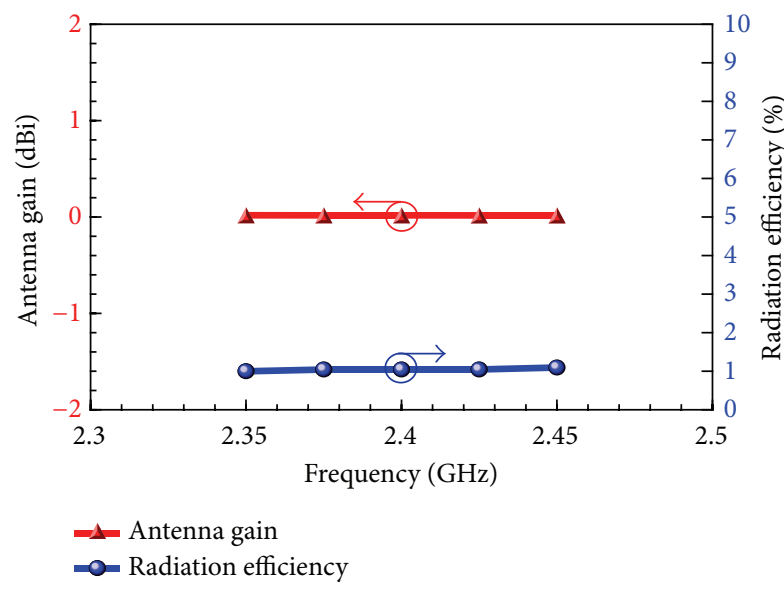

(a)

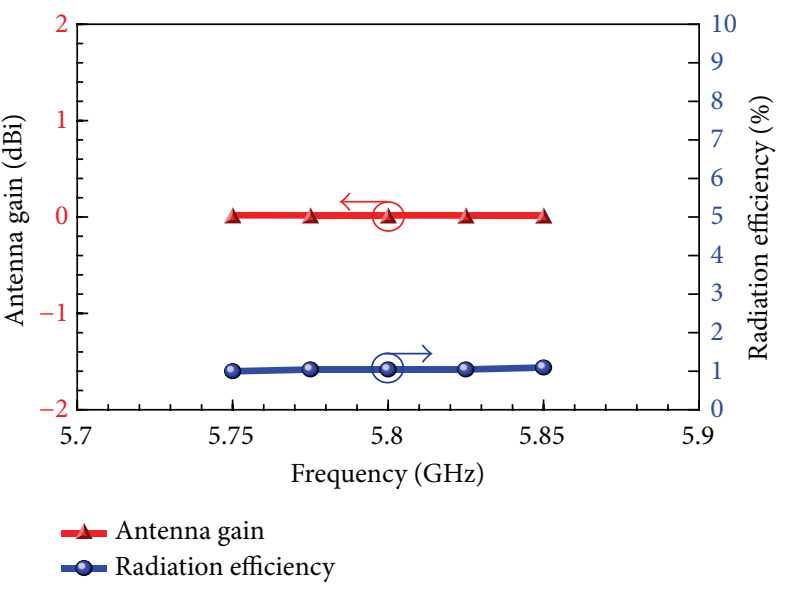

(b)

FIgURE 9: Measured radiation efficiency of the proposed antenna: (a) $2.3-2.5 \mathrm{GHz}$; (b) $5.7-5.9 \mathrm{GHz}$. 


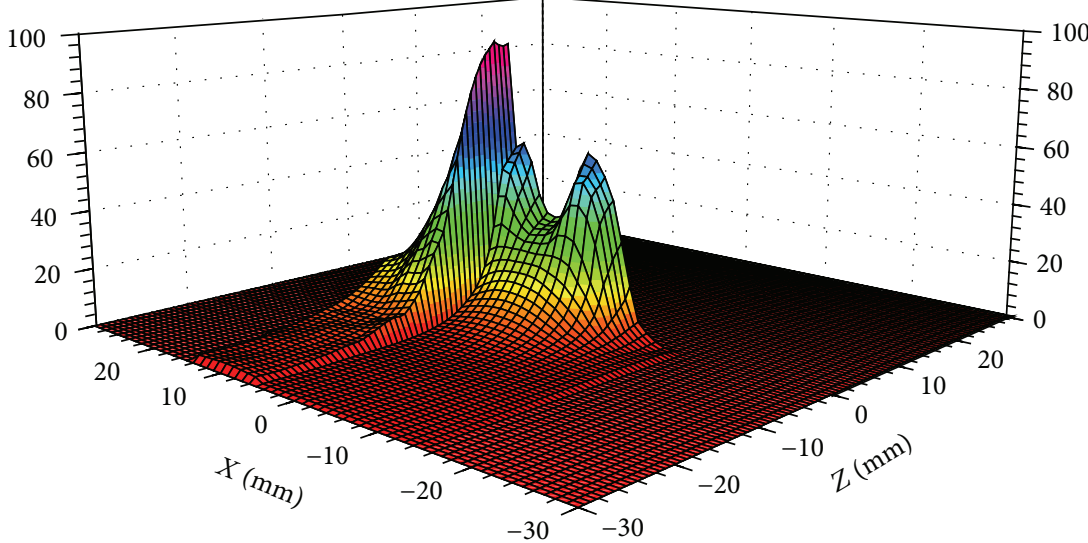

(a)

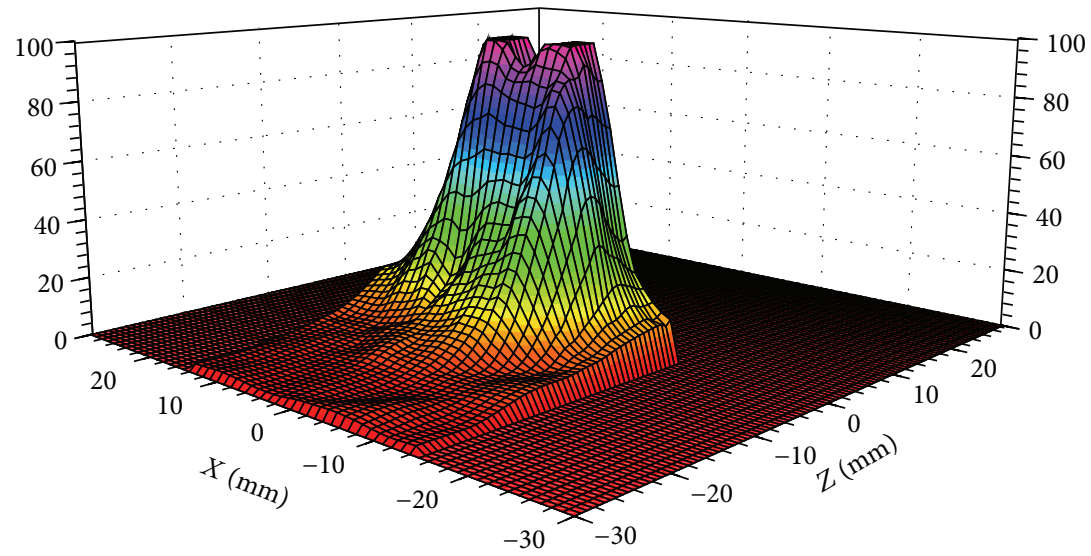

$8.75 E+01+$

$7.95 E+01$ to $8.75 E+01$

$7.16 E+01$ to $7.95 E+01$

$6.36 E+01$ to $7.16 E+01$

$5.57 E+01$ to $6.36 E+01$

$4.77 E+01$ to $5.57 E+01$

$3.98 E+01$ to $4.77 E+01$

$3.18 E+01$ to $3.98 E+01$

$2.39 E+01$ to $3.18 E+01$ ह

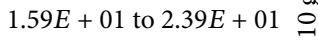

$7.95 E+00$ to $1.59 E+01$

$0.00 E+00$ to $7.95 E+00$

\section{3
3
0
0
0
0
0
0
0
0
0
0
0}

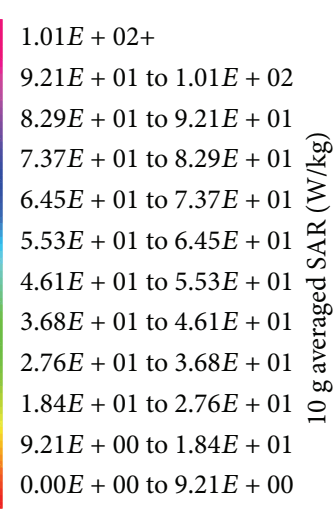

(b)

FIGURE 10: Simulated $10 \mathrm{~g}$ averaged SAR of the proposed antenna: (a) $2.4 \mathrm{GHz}$; (b) $5.8 \mathrm{GHz}$.

small variations and close to $50 \Omega$ impedance matching. The property of small impedance variations also creates broadband characteristic and covers 2.4 and $5.8 \mathrm{GHz}$ for ISM band. Figure 6 shows the simulated $S_{11}$ for different loop sizes of the proposed antenna. From the simulated results, smaller loop excites higher resonant modes, which meet the theory of resonance. Another feature of the proposed design is that the resonant modes are tunable. Figure 7 shows the surface current distributions of the proposed antenna at 2.4 and 5.8 GHz. In Figure 7(a), two zeroes and three poles on the loop form a $1 \lambda$ resonance. At the higher mode (Figure 7(b)), five zeroes and four poles create a $1.5 \lambda$ resonance. To sum up, the proposed design excites two resonant modes to obtain broad operation for ISM band that are verified. Figures 8(a) and 8 (b) present the measured antenna $2 \mathrm{D}$ radiation pattern. In $Y-Z$ plane, the pattern shows near omnidirectional pattern at $2.4 \mathrm{GHz}$. At higher band at $5.8 \mathrm{GHz}$, the patterns are twist and have more zeros. Figure 9 shows the measured antenna radiation gain and efficiency. At 2.4 and $5.8 \mathrm{GHz}$, the antenna gains are stable and close to $0 \mathrm{dBi}$. Besides, the radiation efficiency is also stable and close to $1 \%$ at that band. Because the human body is a lossy dielectric material, the efficiency of the antenna is always small [7]. In Figures 10(a) and 10(b), the simulated $10 \mathrm{~g}$ averaged SAR distributions at ISM band $(2.4$ and $5.8 \mathrm{GHz}$ ) are obtained from the proposed antenna attached on eye tissue.

\section{Conclusions}

This work presents a novel broadband loop antenna design (optimized bandwidth of $4.46 \mathrm{GHz}$ ) for wireless ocular physiological monitoring applications at ISM band (2.4 and $5.8 \mathrm{GHz}$ ). The proposed antenna has advantages of simple geometry and easy fabrication. Another feature of this design is that the resonant modes can be changed by varying the loop size. The simulated and measured results are also suitable for wireless ocular physiological monitoring applications.

\section{Conflict of Interests}

The authors declare that there is no conflict of interests regarding the publication of this paper. 


\section{Acknowledgment}

The authors would like to thank the National Science Council in Taiwan for financial supports (NSC-101-2220-E-006-003).

\section{References}

[1] M. Leonardi, E. M. Pitchon, A. Bertsch, P. Renaud, and A. Mermoud, "Wireless contact lens sensor for intraocular pressure monitoring: assessment on enucleated pig eyes," Acta Ophthalmologica, vol. 87, no. 4, pp. 433-437, 2009.

[2] K. Stangel, S. Kolnsberg, D. Hammerschmidt, B. J. Hosticka, H. K. Trieu, and W. Mokwa, "A programmable intraocular CMOS pressure sensor system implant," IEEE Journal of Solid-State Circuits, vol. 36, no. 7, pp. 1094-1100, 2001.

[3] J. Pandey, Y.-T. Liao, A. Lingley, R. Mirjalili, B. Parviz, and B. P. Otis, "A fully integrated RF-powered contact lens with a single element display," IEEE Transactions on Biomedical Circuits and Systems, vol. 4, no. 6, pp. 454-461, 2010.

[4] Y.-T. Liao, H. Yao, B. Parviz, and B. Otis, "A $3 \mu \mathrm{W}$ wirelessly powered CMOS glucose sensor for an active contact lens," in Proceedings of the IEEE International Solid-State Circuits Conference (ISSCC '11), pp. 38-39, February 2011.

[5] Institute of Applied Physics (IFAC), Nello Carrara, http://niremf.ifac.cnr.it/tissprop/htmlclie/htmlclie.htm.

[6] AnsoftCorporation HFSS, http://www.ansoft.com/products/hf/ hfss/.

[7] J. Kim and Y. Rahmat-Samii, "Implanted antennas inside a human body: simulations, designs, and characterizations," IEEE Transactions on Microwave Theory and Techniques, vol. 52, no. 8, pp. 1934-1943, 2004. 

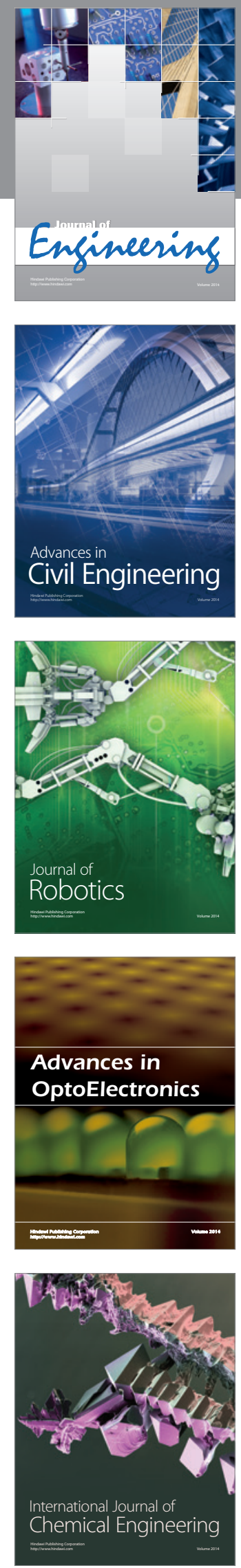

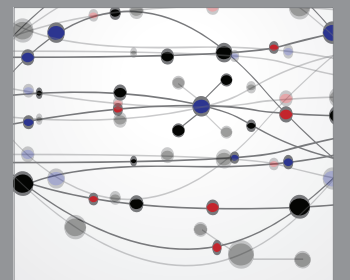

The Scientific World Journal
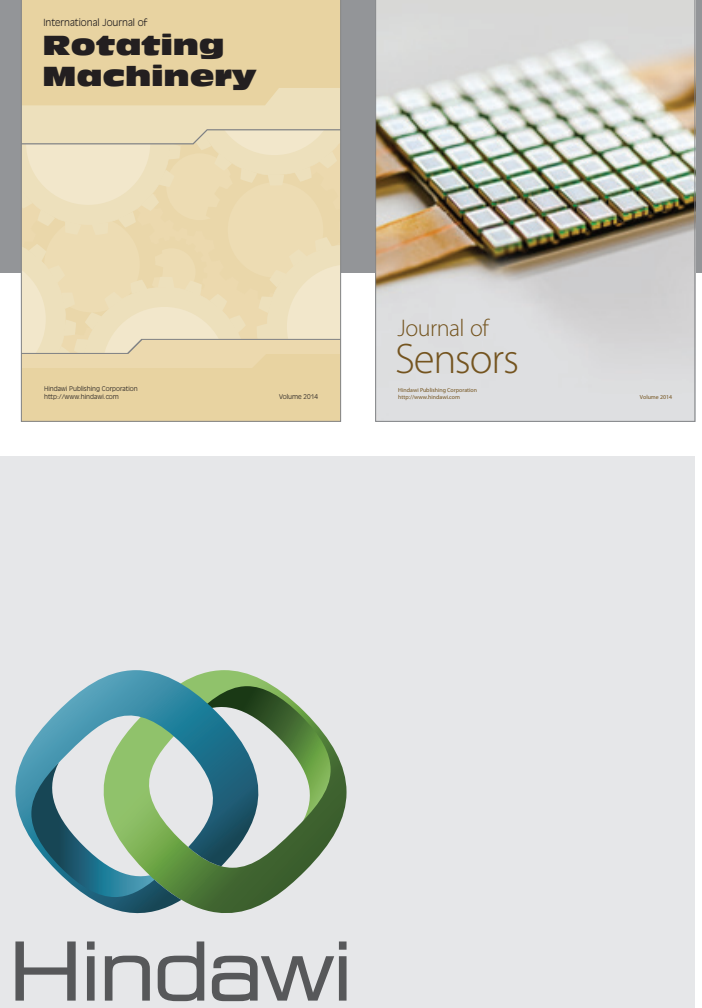

Submit your manuscripts at http://www.hindawi.com
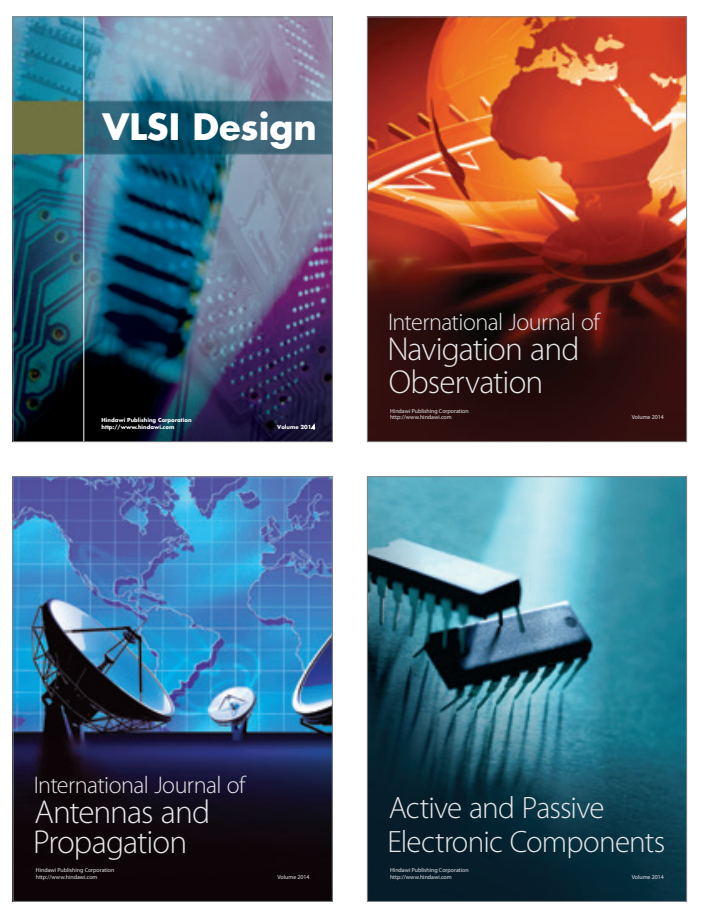
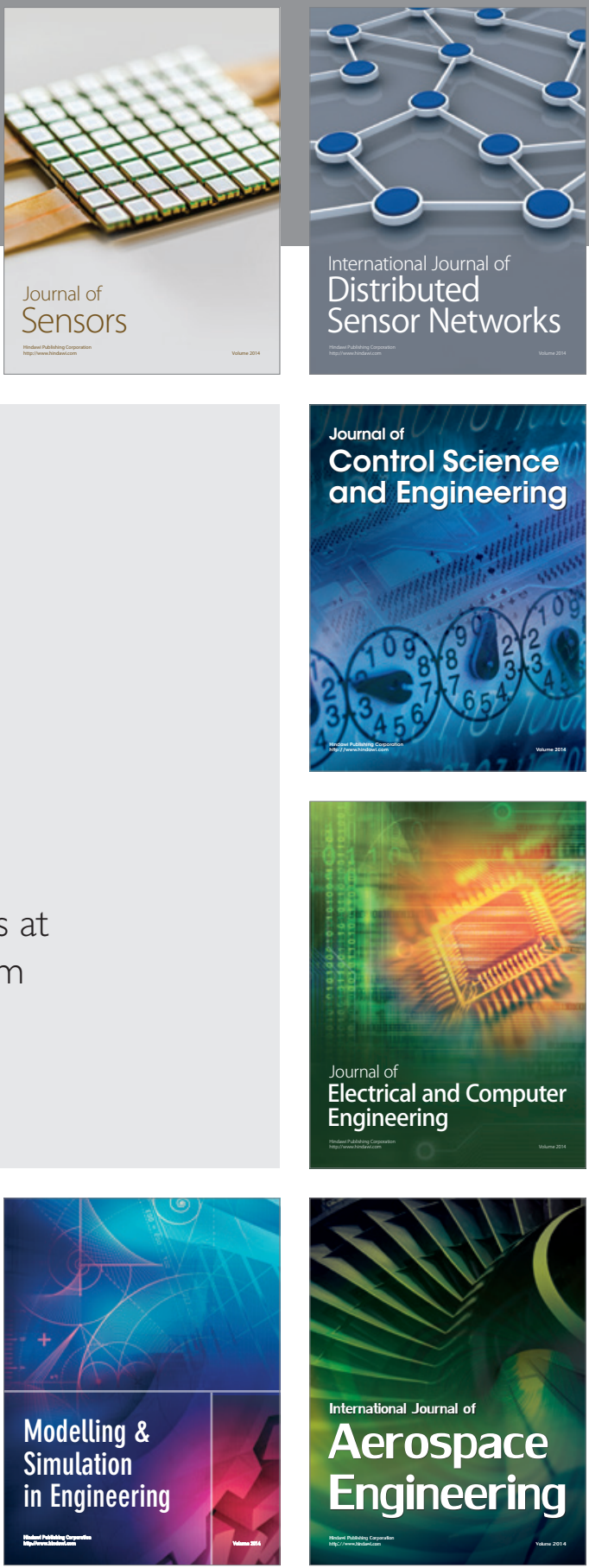

Journal of

Control Science

and Engineering
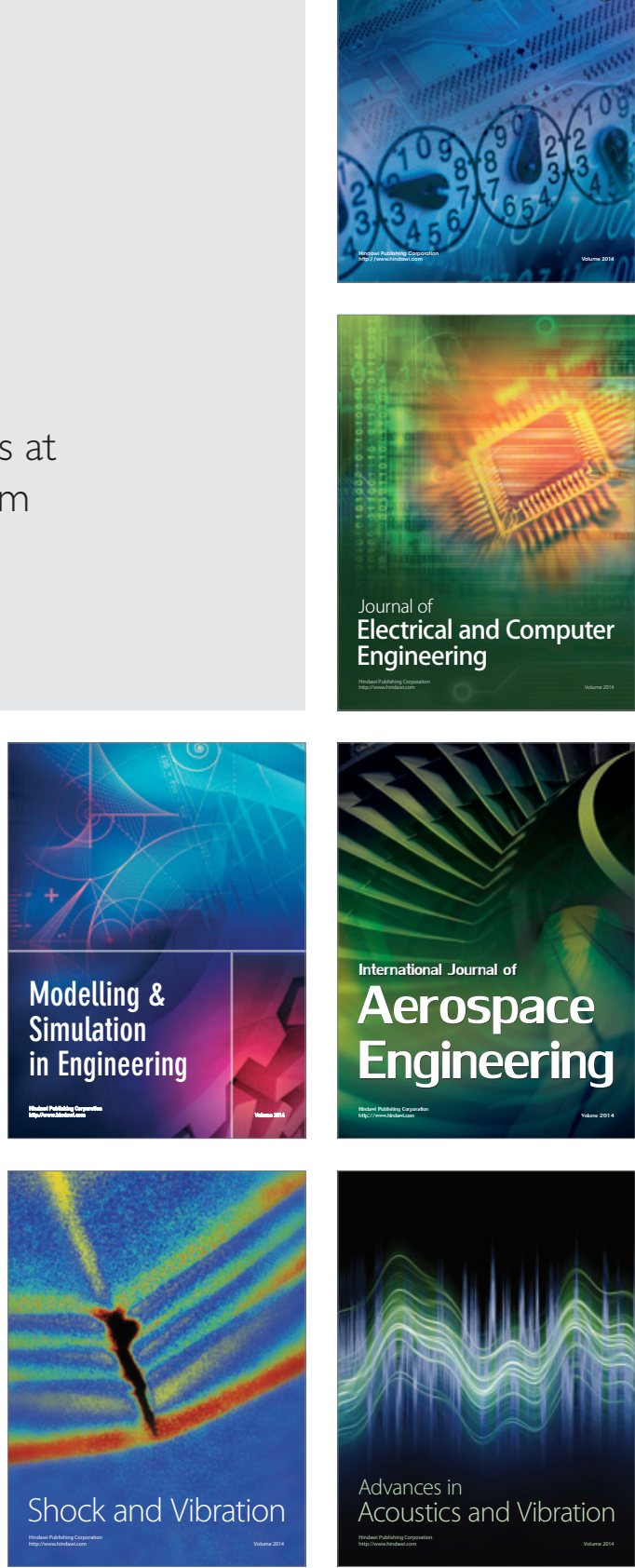